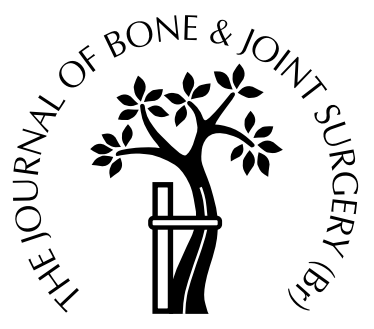

\title{
The extended lateral approach to the hindfoot
}

\author{
ANATOMICAL BASIS AND SURGICAL IMPLICATIONS
}

\author{
Brian J. C. Freeman, Sarah Duff, Patricia E. Allen, \\ Helen D. Nicholson, Roger M. Atkins \\ From Bristol Royal Infirmary and the University of Bristol, England
}

W e have recently described an extended lateral approach to the hindfoot for the operative treatment of displaced intra-articular fractures of the calcaneum. It has the advantage of avoiding damage to the sural nerve and preserving blood supply to allow prompt healing.

We dissected 15 formalin-preserved cadavers, taking photographs to show the structures of the posterolateral aspect of the hindfoot and ankle. We describe a superficial and a deep triangle: the deep triangle contains a constant posterior peroneal artery which supplies the skin of the posterolateral heel. An approach designed to expose the sural nerve will divide this important artery and cause ischaemia of the posterior skin. The extended lateral approach elevates the sural nerve in a thick flap and preserves the blood supply of the skin.

We have reviewed 150 consecutive patients after the use of this approach to study the indications for operation, the quality of wound healing, any damage to the sural nerve and other complications. We recommend the careful use of this approach. Our understanding of its anatomical basis has allowed us to widen the indications for its use.

J Bone Joint Surg [Br] 1998;80-B:139-42.

Received 21 May 1997; Accepted after revision 3 September 1997

B. J. C. Freeman, FRCS Orth, Senior Registrar

Department of Trauma and Orthopaedic Surgery, Queens Medical Centre, University Hospital, Nottingham NG7 2UH, UK.

S. Duff, BM BCh, Senior House Officer

Department of Orthopaedic Surgery, Frenchay Hospital, Beckspool Road, Bristol BS16 1LE, UK.

P. E. Allen, FRCS Orth, Specialist Registrar

R. M. Atkins, MA, DM, FRCS, Consultant Orthopaedic Surgeon

Department of Trauma and Orthopaedic Surgery, Bristol Royal Infirmary, Marlborough Street, Bristol BS2 8HW, UK

H. D. Nicholson, MD, Senior Lecturer in Anatomy

Department of Anatomy, School of Medical Sciences, University of Bristol, Bristol BS8 1TD, UK.

Correspondence should be sent to Mr B. J. C. Freeman at Lindern, 12 Cedar Avenue, Beeston, Nottingham NG9 2HA, UK.

(C)1998 British Editorial Society of Bone and Joint Surgery 0301-620X/98/17987\$2.00
We have recently described an extended lateral approach to the hindfoot for the operative treatment of displaced intraarticular fractures of the calcaneum. ${ }^{1}$ In contrast to the direct lateral approach, ${ }^{2}$ damage to the sural nerve is avoi$\operatorname{ded}^{1,3}$ and healing is prompt, allowing open reduction and internal fixation of calcaneal fractures without soft-tissue complications. The approach is a radical anatomical dissection of a flap involving the skin, the fascia and local muscle with its blood supply. An improved understanding of its anatomical basis has allowed us to widen the indications.

We describe our surgical technique and review 150 consecutive patients.

\section{Patients and Methods}

We dissected 15 cadaver legs (nine female) which had been preserved in formalin; there were ten right legs. None of the specimens had had previous surgery or showed peripheral vascular disease. For clarity, we refer to the artery of supply of the skin to the posterolateral aspect of the heel as the posterior peroneal artery (PPA). ${ }^{4}$ This was usually, but not always (see below) the terminal branch of the peroneal artery after it had given origin to the perforating branch, the communicating branch and the anterior lateral malleolar artery. The dissections of the posterolateral aspect of the hindfoot were photographed in sequence and measurements were made of the positions of relevant structures.

First, the structures superficial to the deep fascia were identified and the distance $\left(\mathrm{d}_{1}\right)$ from the main trunk of the sural nerve to the tip of the lateral malleolus was measured. The deep fascia was then removed to expose the peroneal and flexor compartments including the lateral side of the calcaneum, the flexor hallucis, the peroneal muscles and the arteries within this triangle. The maximum height of this triangle $\left(\mathrm{d}_{2}\right)$ accessible at dissection was measured. Finally, the position of the PPA was noted as it crossed the superior border of the calcaneum. The distance from the lateral malleolus to the artery $\left(\mathrm{d}_{3}\right)$ and the distance from the artery to the calcaneal tendon $\left(\mathrm{d}_{4}\right)$ were also measured.

Operative technique. The skin incision is made by two straight cuts which meet at the lateral side of the heel at an angle of not less than $100^{\circ}$. The distal arm starts over the base of the fifth metatarsal and passes directly posteriorly at 
the upper edge of the thick, specialised heel skin to meet the proximal arm. In patients with a calcaneal fracture, the incision is approximately $1 \mathrm{~cm}$ below the maximally bruised skin.

The proximal part of the incision begins in the posterior midline, at about $12 \mathrm{~cm}$ above the level of the sole and passes in a straight line distally and anteriorly to meet the distal arm about $2 \mathrm{~cm}$ anterior to the line of the heel. The incision is carried directly through the deep fascia with no undermining of skin. For the full extended lateral approach the incision is most easily deepened at its angle, where the calcaneum is readily palpable. The horizontal part of the incision is below the calcaneum and is deepened to the bone. In the distal part, the fascia over the abductor digiti minimi is opened longitudinally and the muscle incised in the line of its fibres. Deep dissection of the proximal arm passes anterior to the calcaneal tendon, and care is taken not to open the paratenon. At its uppermost end the dissection passes around the calcaneal tendon and the lower fibres of gastrocnemius. Since the main trunk of the sural nerve is just anterior to this part of the incision care is required to avoid it.

Subperiosteal dissection of the lateral wall of the calcaneum is limited anterosuperiorly by the peroneal tendons. Subperiosteal division of the inferior peroneal retinaculum allows exposure of the sinus tarsi and the calcaneocuboid joint. Near the posterior facet of the subtalar joint, the posterior calcaneofibular ligament may be included in the subperiosteal dissection, raising the attachment in continuity with the deep fascia and periosteum. This helps to maintain ankle stability; in clinical practice, instability has not been seen.

The flap which is elevated consists of skin, soft tissues, muscle and periosteum and includes the peroneal tendons, sural nerve, PPA and the detached calcaneofibular ligament. It may be held retracted by a stout Kirschner wire in the fibula, to allow dissection of the superficial and deep triangles of the posterolateral aspect of the foot. The plane of this dissection is close to the calcaneal tendon; the deep fascia is incised along the distal part of flexor hallucis. Any arterial trunk or large vein on that muscle is preserved and retracted laterally, since this may represent a PPA which arises aberrantly from the posterior tibial artery. The entire lateral wall of the calcaneum is now exposed.

We have reviewed the case notes of 150 consecutive patients after an extended lateral approach. In all we recorded the indication for operation, the quality of wound healing, the function of the sural nerve and any complications. In 27 patients with calcaneal fractures, metalwork had been removed through the same incision.

\section{Results}

Dissections. The sural nerve was an average of $2.1 \mathrm{~cm}\left(\mathrm{~d}_{1}\right.$ Table I; range 1.5 to 2.6 ) posterior to the tip of the lateral malleolus, on a line from it to the insertion of the calcaneal tendon. This agrees with previous reports ${ }^{5}$ (Fig. 1).

The anatomy of the posterolateral hindfoot is best considered as two triangles, one placed deep to the other. The superficial triangle (Fig. 2) is bounded below by the superior border of the calcaneum, anteriorly by the peroneal tendons, and posteriorly by the calcaneal tendon. It contains fat and the PPA. The deep triangle faces anteromedially from the anterior part of the superficial triangle and is

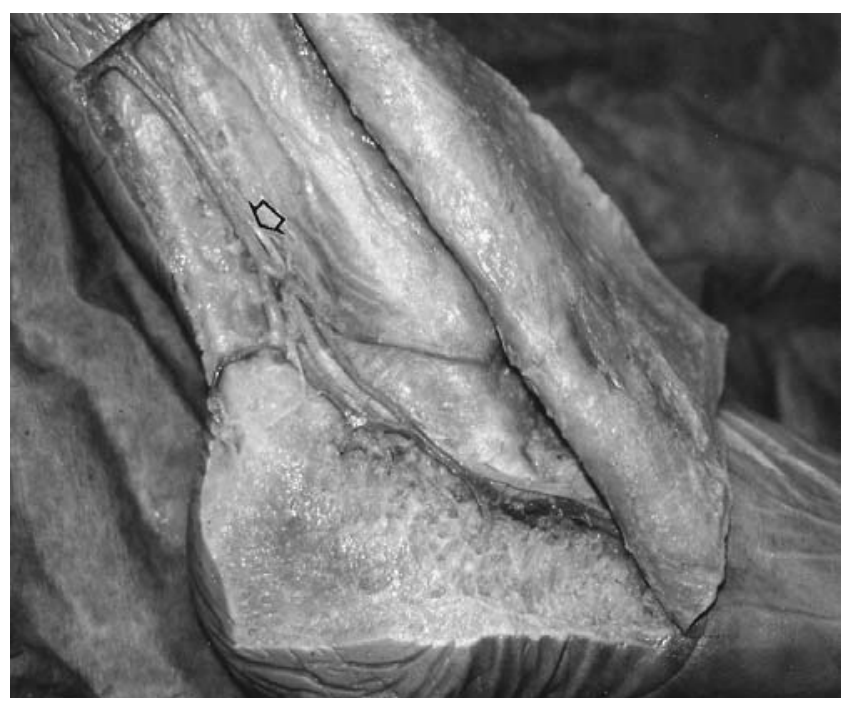

Fig. 1

Superficial dissection of the posterolateral aspect of the right foot and ankle to show the position of the sural nerve (open arrow).

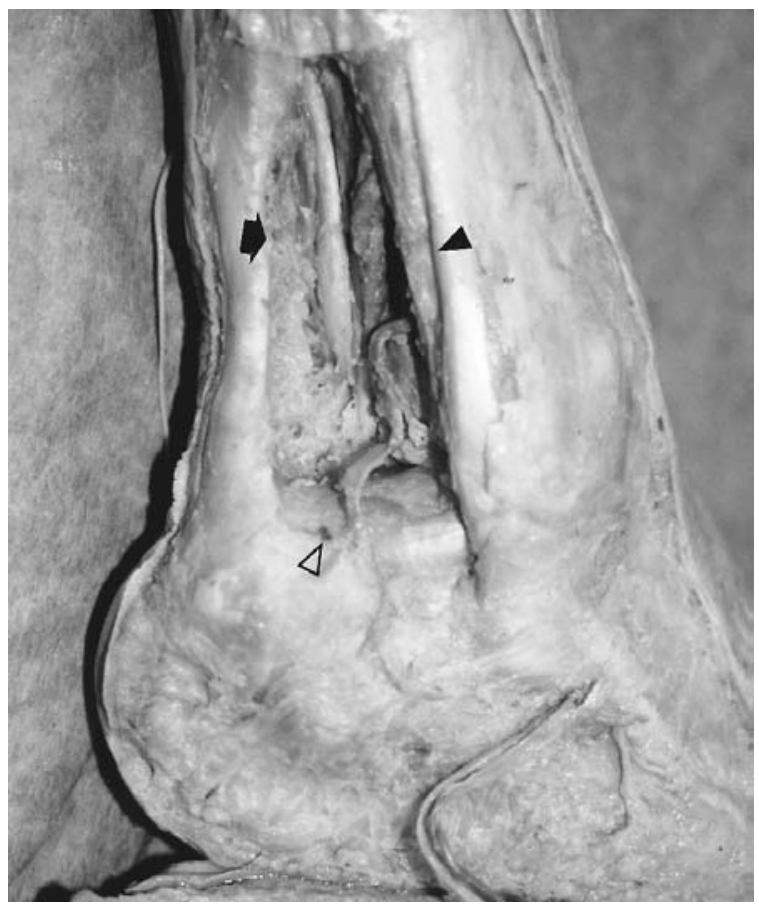

Fig. 2

Deeper dissection showing the superficial triangle, bounded below by the superior border of the calcaneum (open triangle), anteriorly by the peroneal tendons (closed triangle), and posteriorly by the calcaneal tendon (closed arrow). 


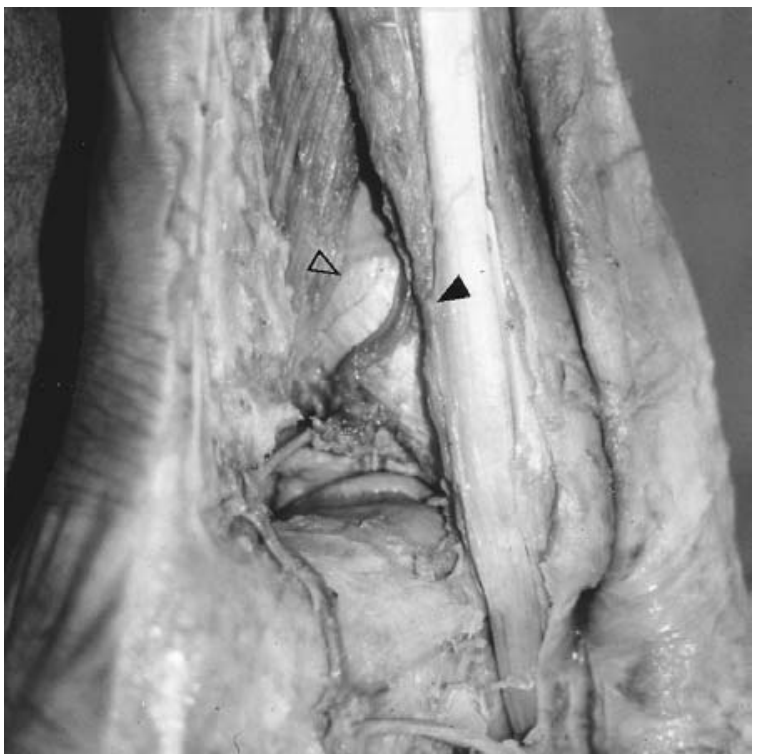

Fig. 3

Dissection showing the deep triangle bounded laterally by the peroneal tendons (closed triangle) and medially by the flexor hallucis muscle (open triangle). The posterior peroneal artery can be seen passing diagonally through the triangle.

entered by dividing the deep fascia. It is bounded below by the superior border of the calcaneum, laterally by the peroneal tendons, and medially by the flexor hallucis muscle (Fig. 3). The superior apex, where flexor hallucis meets the peroneal muscles, was at a mean of $4.1 \mathrm{~cm}\left(\mathrm{~d}_{2}\right.$ Table I; range 3.8 to 5.0 ) above the level of the ankle. The deep triangle contains the deep fascia, the PPA within its own fascial compartment and an anastomosis between the PPA and the posterior tibial artery. The deep fascia of the peroneal compartment is inserted into the fibula and the deep triangle is therefore best opened by incising the fascia over flexor hallucis and reflecting it laterally, protecting the vessels from damage. The PPA was identified as a large vessel in all 15 specimens. In 13 it was a direct continuation of the peroneal artery and in the other two it arose as a definite branch of the posterior tibial artery and entered the deep triangle at 2.2 and $2.7 \mathrm{~cm}$, respectively, above the level of the ankle by winding over the flexor hallucis. In these two specimens it also received anastomotic branches. The PPA passes downwards through the deep triangle, then posterolaterally to exit from the superficial triangle at its inferior border. It crossed the superior border of the calcaneum at a mean of $3.1 \mathrm{~cm}\left(\mathrm{~d}_{3}\right.$ Table $\mathrm{I}$; range 2.6 to 3.6$)$ posterior to the lateral malleolus on a line from it to the insertion of the calcaneal tendon, at about $1.5 \mathrm{~cm}$ anterior to the tendon $\left(\mathrm{d}_{4}\right.$ Table $\mathrm{I}$; range 1.1 to 2.0$)$. At this level, it was always posterior to the sural nerve by about $1 \mathrm{~cm}(0.4$ to 1.4). It always crossed deep to the sural nerve and became superficial on the posterolateral aspect of the heel.

Our dissections confirmed that a vertical incision which seeks to identify the sural nerve will divide the PPA. In all specimens this terminated as anterior and posterior branches on the lateral side of the heel. In 14 specimens the anterior branch was deep to the posterior calcaneofibular ligament. In one specimen it passed superficial to this ligament.

Clinical review. We reviewed 150 consecutive patients who had the extended lateral approach for fixation of displaced intra-articular fractures of the calcaneum, reconstructive subtalar arthrodesis, fracture of the talus, or posterior malleolar fracture associated with lateral fractures (Table II). In addition, 27 of these patients with calcaneal fractures had metal removed through the same incision, with rapid wound healing and no infection in any of them.

The only complications were seen in patients after the internal fixation of acute calcaneal fractures. These included haematoma, minor necrosis of the edge of the flap and some major problems of wound healing (Table III). There was no permanent dysfunction of the sural nerve, although four patients had temporary paraesthesiae. One patient with bilat-

Table I. Results from dissections in 15 cadaver specimens

\begin{tabular}{|c|c|c|c|c|c|c|c|}
\hline Specimen & Side & Gender & $\begin{array}{l}\text { Distance }\left(d_{1}\right) \\
\text { lat malleolus } \\
\text { to sural nerve } \\
(\mathrm{cm})\end{array}$ & $\begin{array}{l}\text { Max height of } \\
\text { triangle }\left(d_{2}\right) \\
(\mathrm{cm})\end{array}$ & $\begin{array}{l}\text { Distance }\left(d_{3}\right) \\
\text { lat malleolus } \\
\text { to artery } \\
(\mathrm{cm})\end{array}$ & $\begin{array}{l}\text { Distance }\left(d_{4}\right) \\
\text { tendo Achillis } \\
\text { to artery } \\
(\mathrm{cm})\end{array}$ & Artery origin \\
\hline 1 & $\mathrm{R}$ & M & 2.2 & 3.9 & 3.1 & 1.6 & Peroneal \\
\hline 2 & $\mathrm{~L}$ & M & 2.1 & 3.8 & 3.3 & 1.3 & Peroneal \\
\hline 3 & $\mathrm{R}$ & M & 2.4 & 5.0 & 3.3 & 2.0 & Peroneal \\
\hline 4 & $\mathrm{R}$ & $\mathrm{F}$ & 2.0 & 4.4 & 3.0 & 1.8 & Post tibial \\
\hline 5 & $\mathrm{R}$ & M & 1.8 & 3.8 & 3.2 & 1.6 & Peroneal \\
\hline 6 & $\mathrm{~L}$ & $\mathrm{~F}$ & 2.2 & 3.8 & 2.6 & 1.1 & Peroneal \\
\hline 7 & $\mathrm{R}$ & $\mathrm{F}$ & 1.5 & 3.8 & 2.9 & 1.3 & Post tibial \\
\hline 8 & $\mathrm{~L}$ & $\mathrm{~F}$ & 1.8 & 4.1 & 3.1 & 1.2 & Peroneal \\
\hline 9 & $\mathrm{R}$ & $\mathrm{F}$ & 2.3 & 4.1 & 3.5 & 1.4 & Peroneal \\
\hline 10 & $\mathrm{R}$ & $\mathrm{F}$ & 2.2 & 3.8 & 3.4 & 1.4 & Peroneal \\
\hline 11 & $\mathrm{~L}$ & $\mathrm{~F}$ & 2.1 & 4.4 & 2.9 & 1.6 & Peroneal \\
\hline 12 & $\mathrm{R}$ & M & 2.3 & 4.0 & 3.6 & 1.6 & Peroneal \\
\hline 13 & $\mathrm{R}$ & $\mathrm{F}$ & 2.6 & 4.2 & 3.4 & 1.3 & Peroneal \\
\hline 14 & $\mathrm{~L}$ & $\mathrm{~F}$ & 2.1 & 4.3 & 3.2 & 1.5 & Peroneal \\
\hline 15 & $\mathrm{R}$ & $\mathrm{F}$ & 2.1 & 3.9 & 2.6 & 1.5 & Peroneal \\
\hline Mean & & & 2.1 & 4.1 & 3.1 & 1.5 & \\
\hline
\end{tabular}


Table II. Clinical review of 150 consecutive cases

\begin{tabular}{lc}
\hline Indications for the extended lateral approach & Number \\
\hline Acute fixation of displaced calcaneal fractures & 134 \\
Reconstructive subtalar arthrodesis & 10 \\
Fractures of the talus & 4 \\
Fractures of the posterior malleolus & 2
\end{tabular}

Table III. Complications of the extended lateral approach in 150 cases

\begin{tabular}{ll}
\hline Complications of the extended lateral approach & Number \\
\hline Superficial infection (responding to antibiotics) & 6 \\
Infected haematomas & 2 \\
Flap edge necrosis & 3 \\
Rotation flap & 1 \\
Reconstructive free flaps & 3 \\
Major sural nerve deficit & 0 \\
\hline
\end{tabular}

eral grossly displaced calcaneal fractures had such severe swelling that the proximal arms of the wounds could not be closed, but both healed well by secondary intention. Four patients had major breakdown of the wound requiring plastic surgery; three had a free flap and the fourth had a local rotation flap. Two of these patients were persistent smokers, and care should be taken in this group, even if the vascular supply to the feet is intact. Two of the wound haematomas became infected; one responded to drainage and antibiotics and the other to antibiotics and the removal of metal.

\section{Discussion}

A medial approach to the calcaneum gives adequate exposure for fractures of the medial wall, ${ }^{6}$ but allows only indirect reduction of the lateral joint fragment which often contains a considerable portion of the posterior facet. ${ }^{7}$

Lateral approaches to the calcaneum were popularised by Palmer, ${ }^{2}$ particularly the direct lateral approach or modified Kocher's incision which provides direct exposure of the articular components of the calcaneum. ${ }^{8}$ This approach is associated with frequent necrosis of the wound edge, and with infection and damage to the sural nerve. 1,3 Many surgeons prefer an L-shaped extensile approach, ${ }^{1,3,9,10}$ but in the past the reduction in wound problems has been ascribed to the avoidance of bruised tissues by this incision. ${ }^{1}$

Our anatomical study showed other reasons for the improved surgical outcome of an extended lateral approach. The siting of the skin incision is critical if damage to the sural nerve is to be avoided. Some published diagrams are misleading, ${ }^{9,10}$ since the proximal arm should run almost to the midline posteriorly. ${ }^{11}$ The approach involves elevation of a thick flap of skin, muscle and fascia; preservation of the blood supply to this flap is of greater importance than the avoidance of bruised skin.

The blood supply to the skin of the heel has been described previously. ${ }^{4,12,13}$ Salmon $^{4}$ showed that there is a watershed on its lateral side between the cutaneous arterial territories of the PPA superiorly and the lateral plantar artery inferiorly. The posterior watershed is between the PPA and the region supplied by the posterior tibial artery. This watershed is exploited by the extended lateral approach. Carr, Hansen and Benirschke ${ }^{14}$ reported that a posterior longitudinal incision to locate and identify the sural nerve often breaks down, but explained this as due to previous soft-tissue damage before the delayed reconstruction of a calcaneal fracture. Our dissections suggest that this incision probably divides the PPA and makes the posterior skin ischaemic.

An understanding of the anatomy has allowed us to exploit the extended lateral approach, not only for the surgical treatment of all displaced intra-articular fractures of the calcaneum but also for delayed subtalar reconstructive arthrodesis. We use the vertical limb of this incision increasingly for the surgical treatment of fractures of the talus since, unlike anterior approaches, it does not cause further damage to the blood supply of the talus. The approach is also useful for the fixation of posterior malleolar fractures associated with lateral malleolar fractures. We have seen relatively few complications, and recommend its careful use.

No benefits in any form have been received or will be received from a commercial party related directly or indirectly to the subject of this article.

References

1. Eastwood DM, Atkins RM. Lateral approaches to the heel: a comparison of two incisions for the fixation of calcaneal fractures. The Foot 1992;2:143-7.

2. Palmer I. The mechanism and treatment of fractures of the calcaneus: open reduction with the use of cancellous grafts. J Bone Joint Surg [Am] 1948;30-A:2-8.

3. Sanders R, Fortin P, DiPasquale T, Walling A. Operative treatment in 120 displaced intra-articular calcaneal fractures: results using a prognostic computed tomography scan classification. Clin Orthop 1993;290:87-95.

4. Salmon M. Descriptions of the cuaneous arteries. In: Arteries of the skin. New York: Churchill Livingstone, 1988:35-71.

5. Eastwood DM, Irgau I, Atkins RM. The distal course of the sural nerve and its significance for incisions around the lateral hindfoot. Foot Ankle 1992;13:199-202.

6. McReynolds IS. Trauma to the os calcis and heel cord. In: Jahss, MH, ed. Disorders of the foot. Vol. 2. Philadelphia, etc. W. B. Saunders Co, 1982:1497-1542.

7. Eastwood DM, Gregg PJ, Atkins RM. Intra-articular fractures of the calcaneum. Part I: pathological anatomy and classification. J Bone Joint Surg [Br] 1993;75-B:183-8.

8. Stephenson JR. Surgical treatment of displaced intra-articular fractures of the calcaneus: a combined lateral and medial approach. Clin Orthop 1993;290:68-75.

9. Benirschke SK, Sangeorzan BJ. Extensive intraarticular fractures of the foot: surgical management of calcaneal fractures. Clin Orthop 1993;292;128-34.

10. Zwipp H, Tscherne H, Thermann H, Weber T. Osteosynthesis of displaced intra-articular fractures of the calcaneus: results in 123 cases. Clin Orthop 1993;290:76-86.

11. Eastwood DM, Phipp L. Intra-articular fractures of the calcaneum: why such controversy? Injury 1997;28:247-59.

12. Taylor GI, Palmar JH. The vascular territories (angiosomes) of the body: experimental study and clinical applications. Br J Plast Surg 1987; 40:113-41.

13. Hall RL, Shereff MJ. Anatomy of the calcaneus. Clin Orthop 1993; 290:27-35.

14. Carr JB, Hansen ST, Benirschke SK. Subtalar distraction bone block fusion for late complications of os calcis fractures. Foot Ankle 1988; 9:81-6. 